\title{
Major nerve injury after contraceptive implant removal: case illustration
}

\author{
Carlos E. Restrepo, MD, and Robert J. Spinner, MD \\ Department of Neurosurgery, Mayo Clinic, Rochester, Minnesota \\ http://thejns.org/doi/abs/10.3171/2015.1.JNS142642 \\ KEY WORDS contraceptive implant; nerve injury; median nerve; ulnar nerve; peripheral nerve
}

\begin{abstract}
A N obese 19-year-old woman presented 3 months after concomitant removal of an ovarian cyst and an expired contraceptive device, which had been in her dominant left arm (Fig. 1A). The obstetrician had noted resistance after pulling on a nerve rather than the implant. Immediately postoperatively, the patient had noted marked finger and hand weakness, sensory loss, and severe radiating pain. Physical and electrophysiological examinations revealed a complete median and a moderate ulnar nerve lesion. Ultrasound revealed a fusiform enlargement involving $90 \%$ of the median nerve consistent with a neuroma in continuity (Fig. 1B) and enlargement of an ulnar nerve fascicle.

Surgical exploration was performed 2 months later due to lack of improvement. The medial antebrachial cutaneous and ulnar nerves were mildly scarred, and the median nerve had a $5-\mathrm{cm}$ neuroma in continuity. No nerve action potential was recorded across the median nerve lesion, but a compound motor action potential was present in the flexor carpi radialis and pronator teres muscles. External neurolysis of these nerves was performed over approximately $17 \mathrm{~cm}$ (Fig. $1 \mathrm{C}$ and $\mathrm{D})$. Some improvement in median nerve function was evident immediately after surgery. Follow-up showed continued improvement. At 11 months, median nerve function in extrinsic and intrinsic muscles was MRC Grade 4 and ulnar nerve function had normalized. Sequential postoperative electromyographies documented reinnervation of both nerves.

Contraceptive implants are designed for easy
\end{abstract}

subdermal insertion and removal under local anesthesia through a small incision over the medial aspect of the arm. ${ }^{1}$ Rare cases of associated nerve injury, usually limited to cutaneous nerves, have been reported..$^{2-5}$ We present the first known case involving 2 major nerves. This case illustrates that even the simplest of procedures can have serious complications.

\section{References}

1. Fischer MA: Implanon: a new contraceptive implant. J Obstet Gynecol Neonatal Nurs 37:361-368, 2008

2. Hueston WJ, Locke KT: Norplant neuropathy: peripheral neurologic symptoms associated with subdermal contraceptive implants. J Fam Pract 40:184-186, 1995

3. Osman N, Dinh A, Dubert T, Goubier JN: [A new cause for iatrogenic lesion of the ulnar nerve at the arm: contraceptive hormonal implant. Report of two cases.] Chir Main 24:181-183, 2005 (Fr)

4. Smith JM, Conwit RA, Blumenthal PD: Ulnar nerve injury associated with removal of Norplant implants. Contraception 57:99-101, 1998

5. Wechselberger G, Wolfram D, Pülzl P, Soelder E, Schoeller T: Nerve injury caused by removal of an implantable hormonal contraceptive. Am J Obstet Gynecol 195:323-326, 2006

\section{Author Contributions \\ Conception and design: both authors. Acquisition of data: both authors. Critically revising the article: both authors. Approved the final version of the manuscript on behalf of both authors: Spinner.}



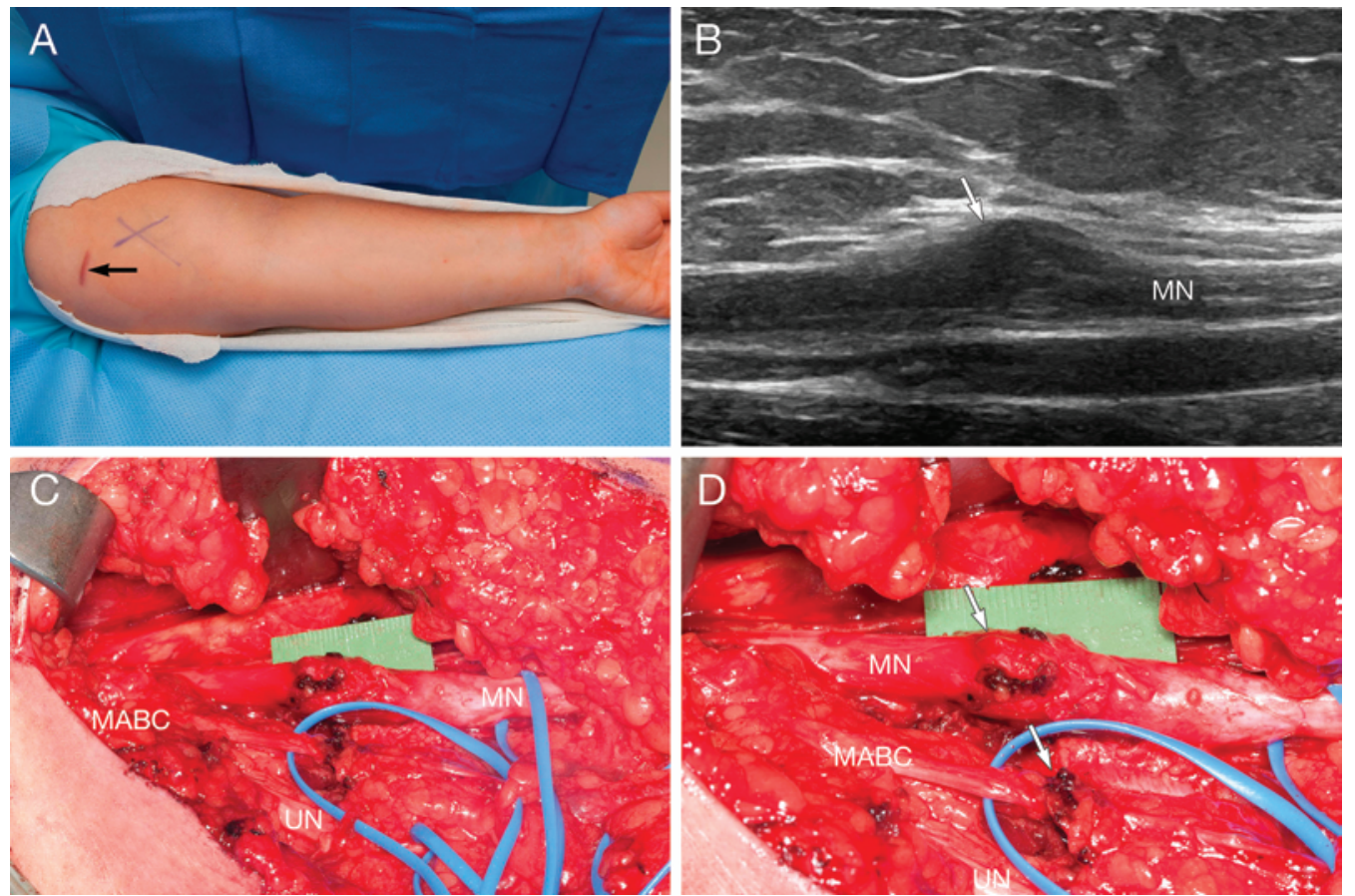

FIG. 1. A: Preoperative photograph showing previous incision (black arrow). The " $X$ " is both the preoperative site marking and the location of percussion tenderness for the median nerve. B: Preoperative ultrasonogram showing the median nerve (MN) neuroma (white arrow). C: Intraoperative findings showing the injured MN, ulnar nerve (UN), and medial antebrachial cutaneous (MABC) nerve. D: Close-up of the neuromas of the MN and MABC nerve (arrows). 